\title{
Brittle Deformation Sequence at Dead Indian Hill \& the Heart Mountain Detachment
}

G. Graham Ellsworth (gglswrt@memphis.edu) and Mervin J. Bartholomew (jbrthlm1@memphis.edu)

\section{Department of Earth Science - The University of Memphis, Memphis, TN, 38152}

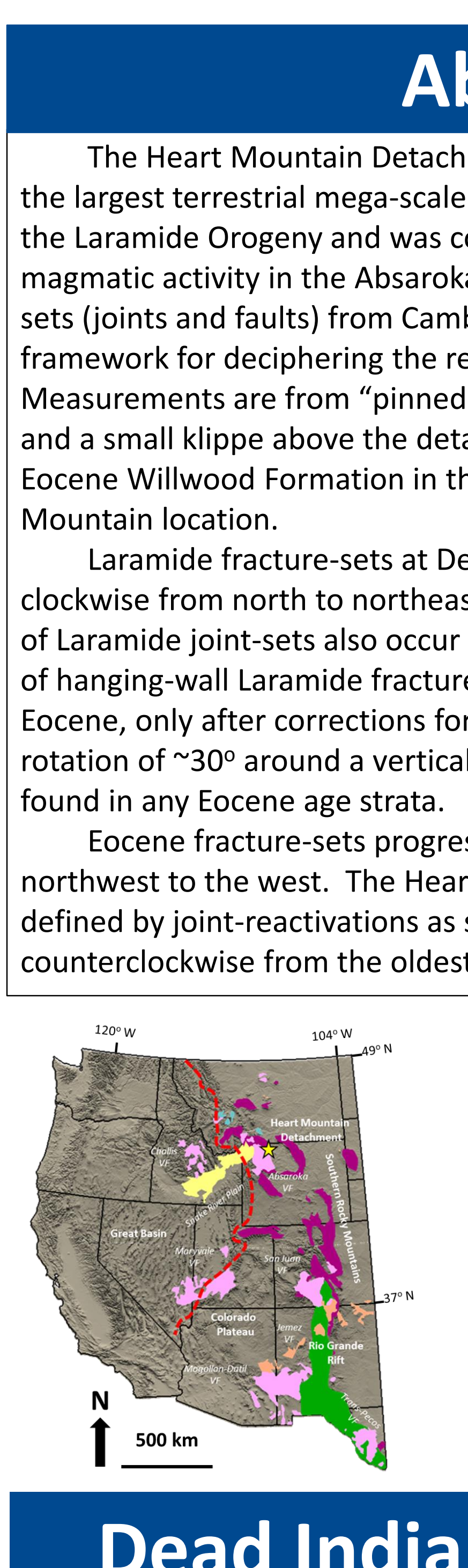

Dead Indian Hill Laramide Fracture-Sets: Pre-Heart Mountain Detachment Sub-Detachment Fracture-Sets: pinned to basement stratigraphy

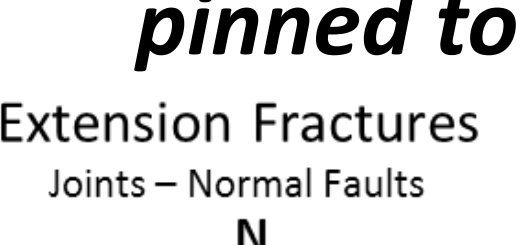

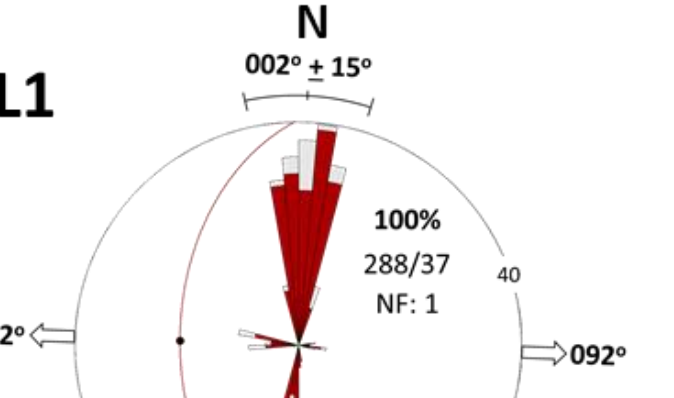

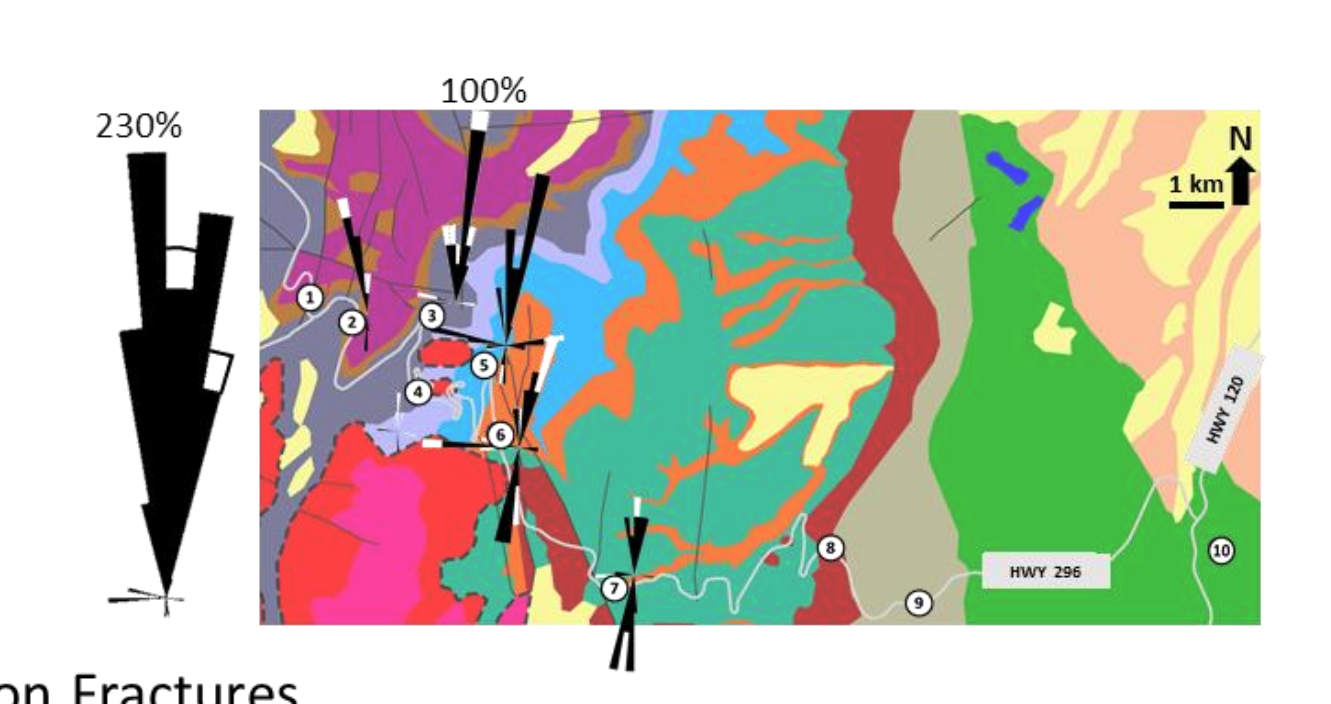

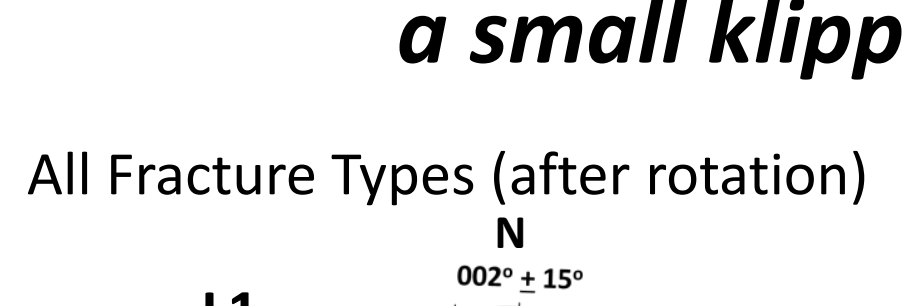
All Fracture Types (after rotation)

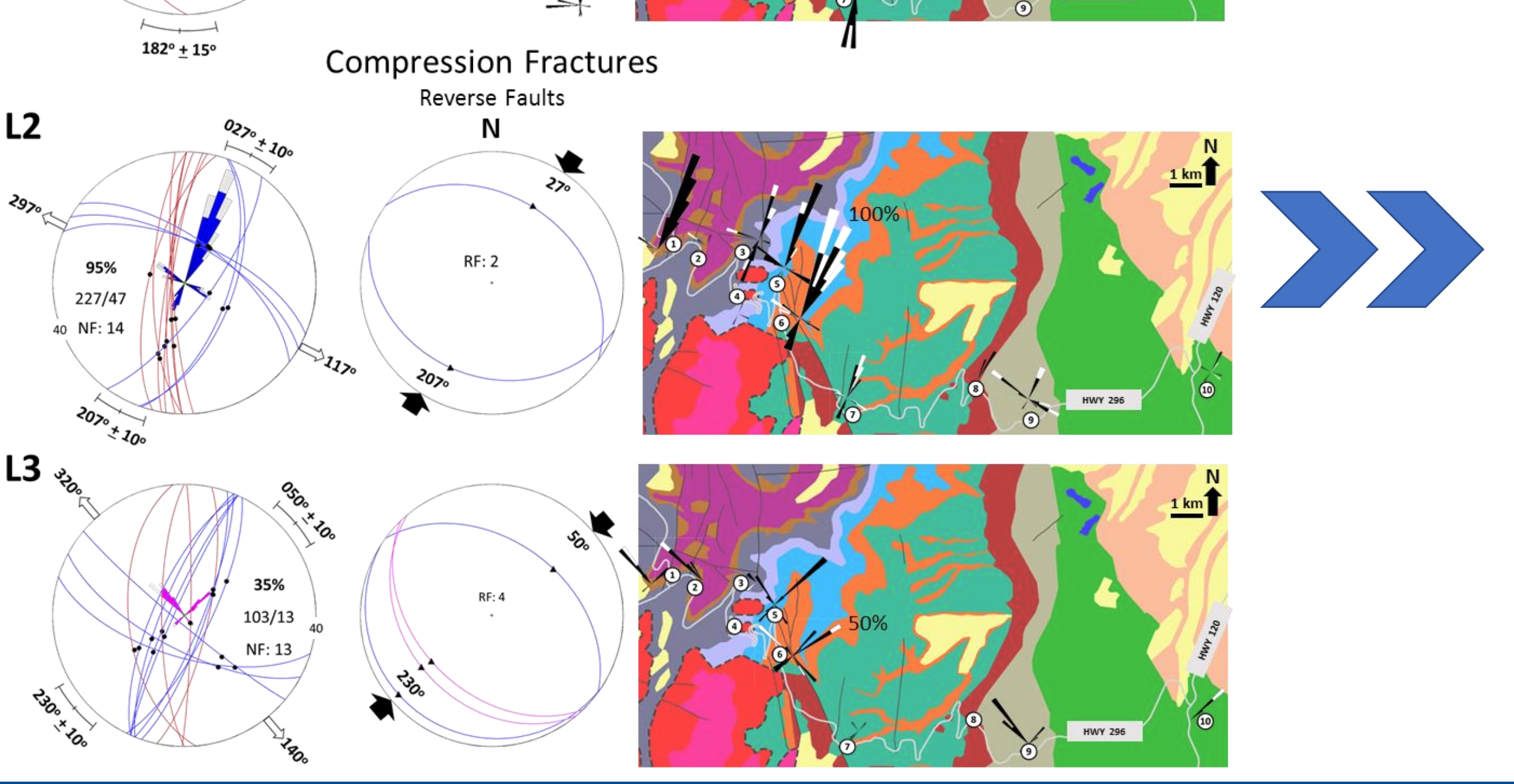

Dead Indian Hill: Eocene Fracture-Sets: Pre-Heart Mountain Detachment
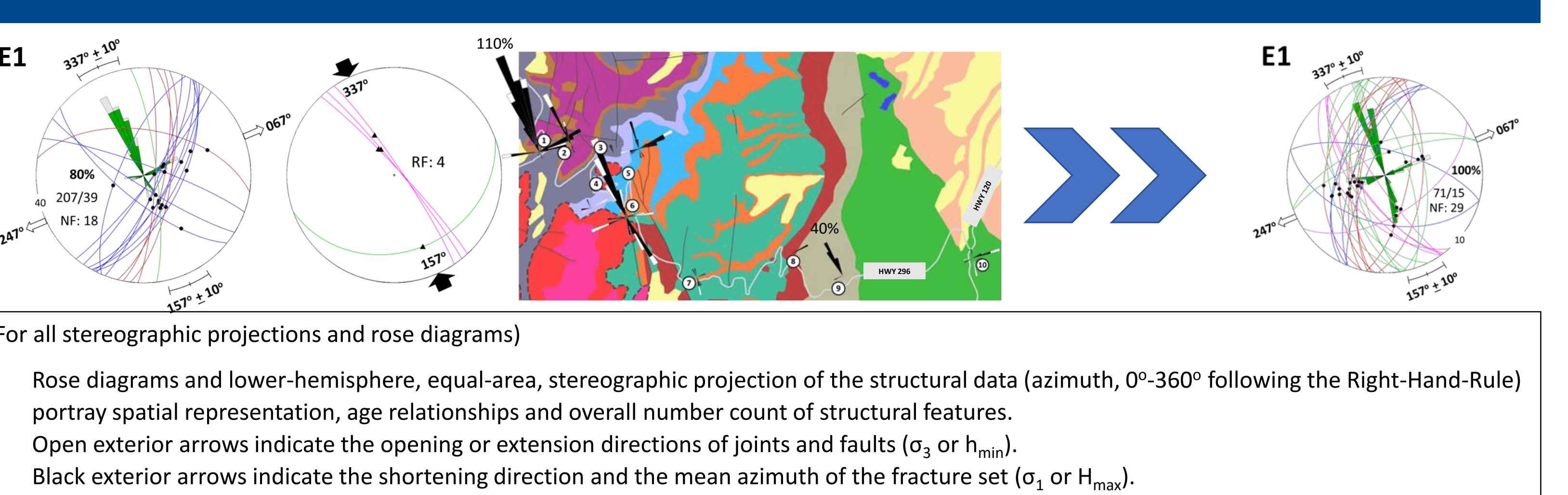

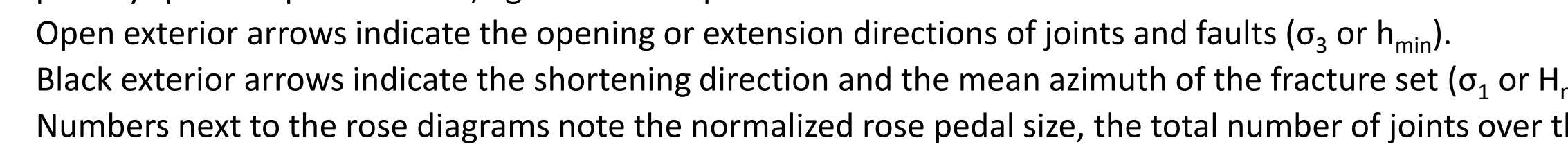

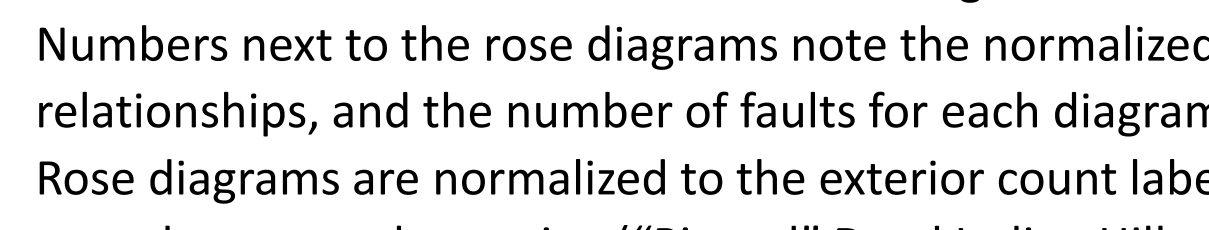

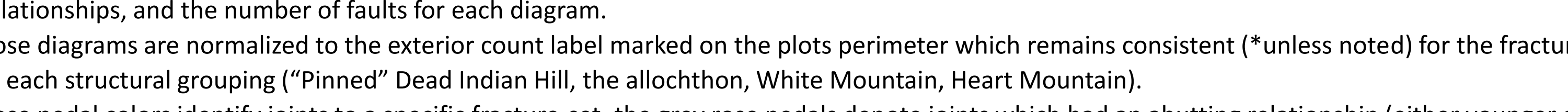

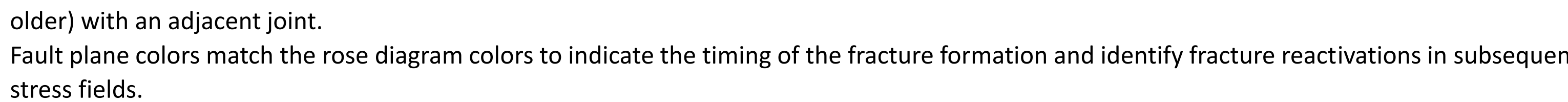

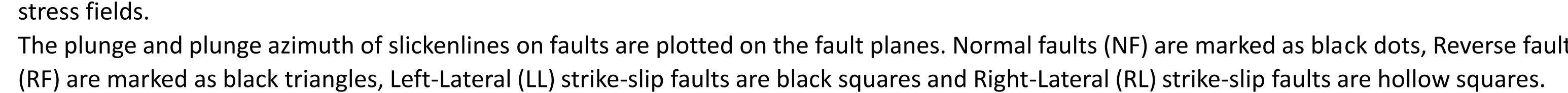

Fracture Sets within the Allochthon:
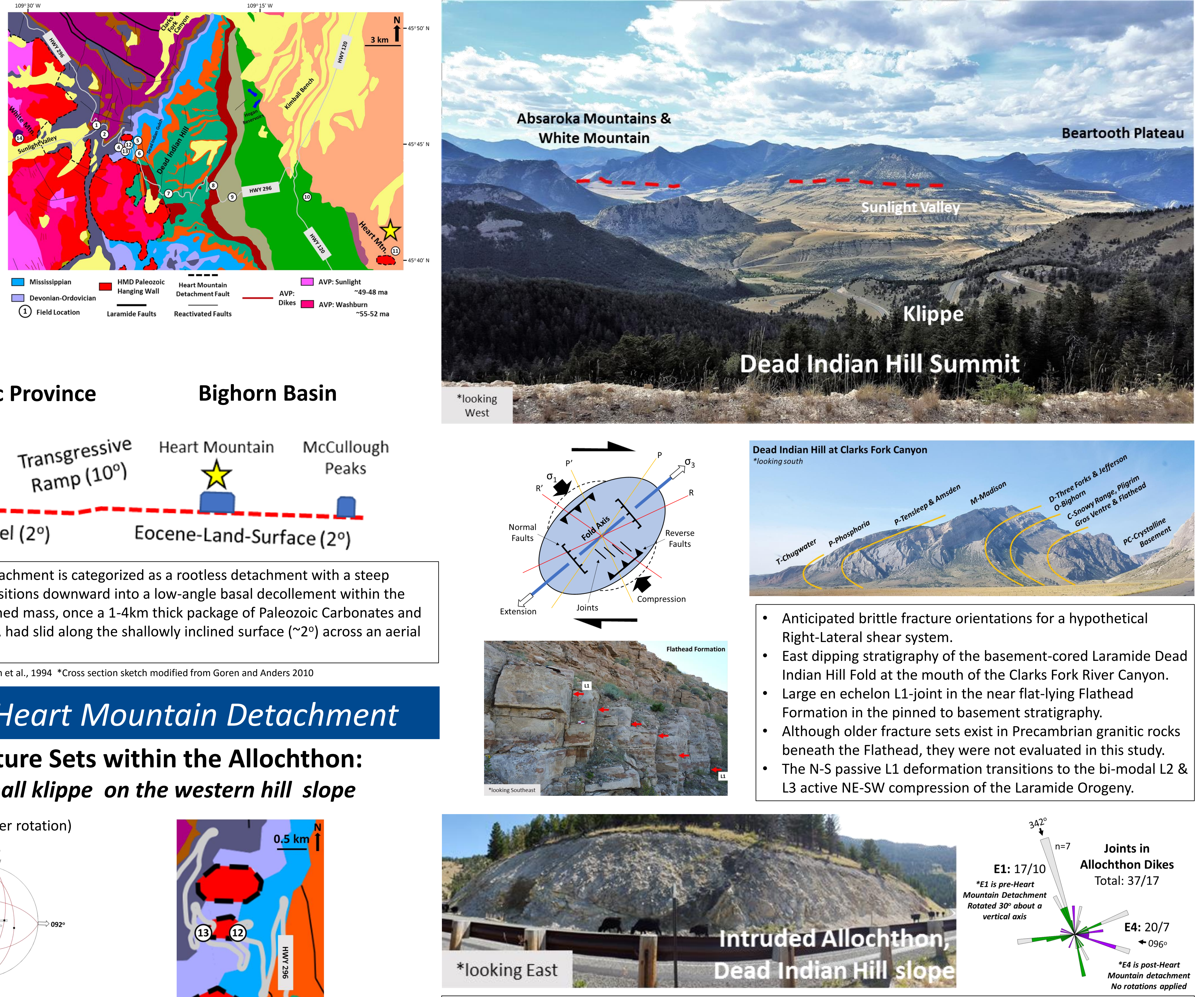
* *ooking East After restoration of the allochthon's bedding to horizontal, the same laramide and oldest Eocen fracture-

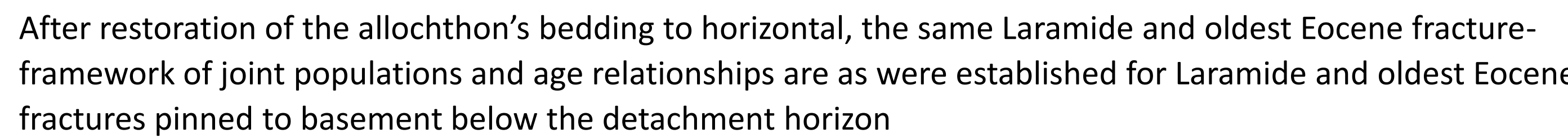
Furthermore, the similarity of joint-orientation and the relativiv fracture-sequence can be used to determine how
much rotation about a vertical axis occurred after as the detachment sid, relative to the pined counterparts. - The Madison Limestone and Bighorn Dolomite units in the allochthon road-cut show a clockwise rotation of $300^{\circ}$
lo match the three bulk joint trends in pimed Dead Indian Hill strata.

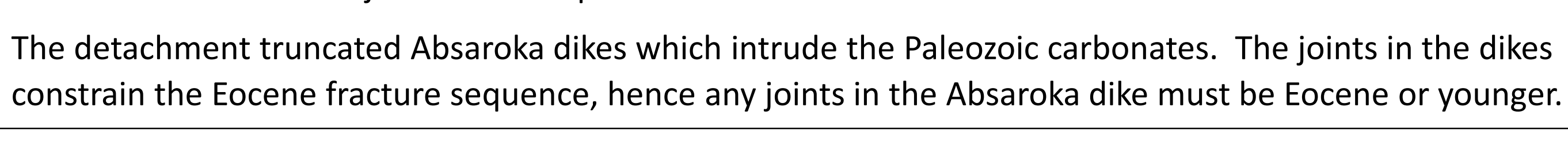
Bedding

$\sum_{210}^{13}$

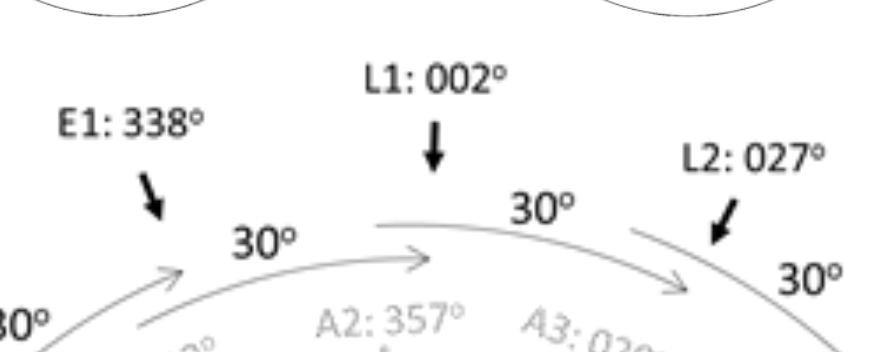
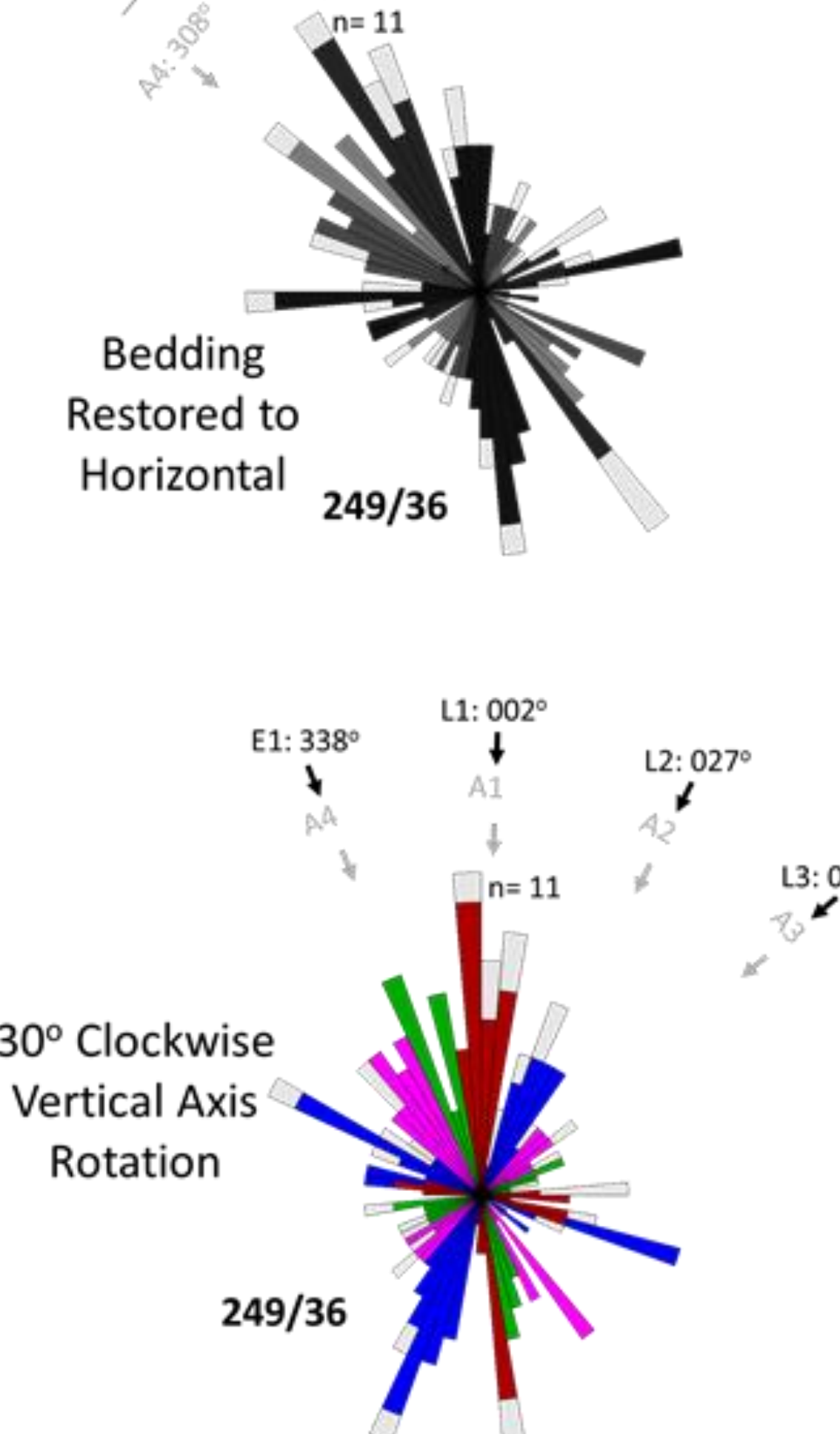

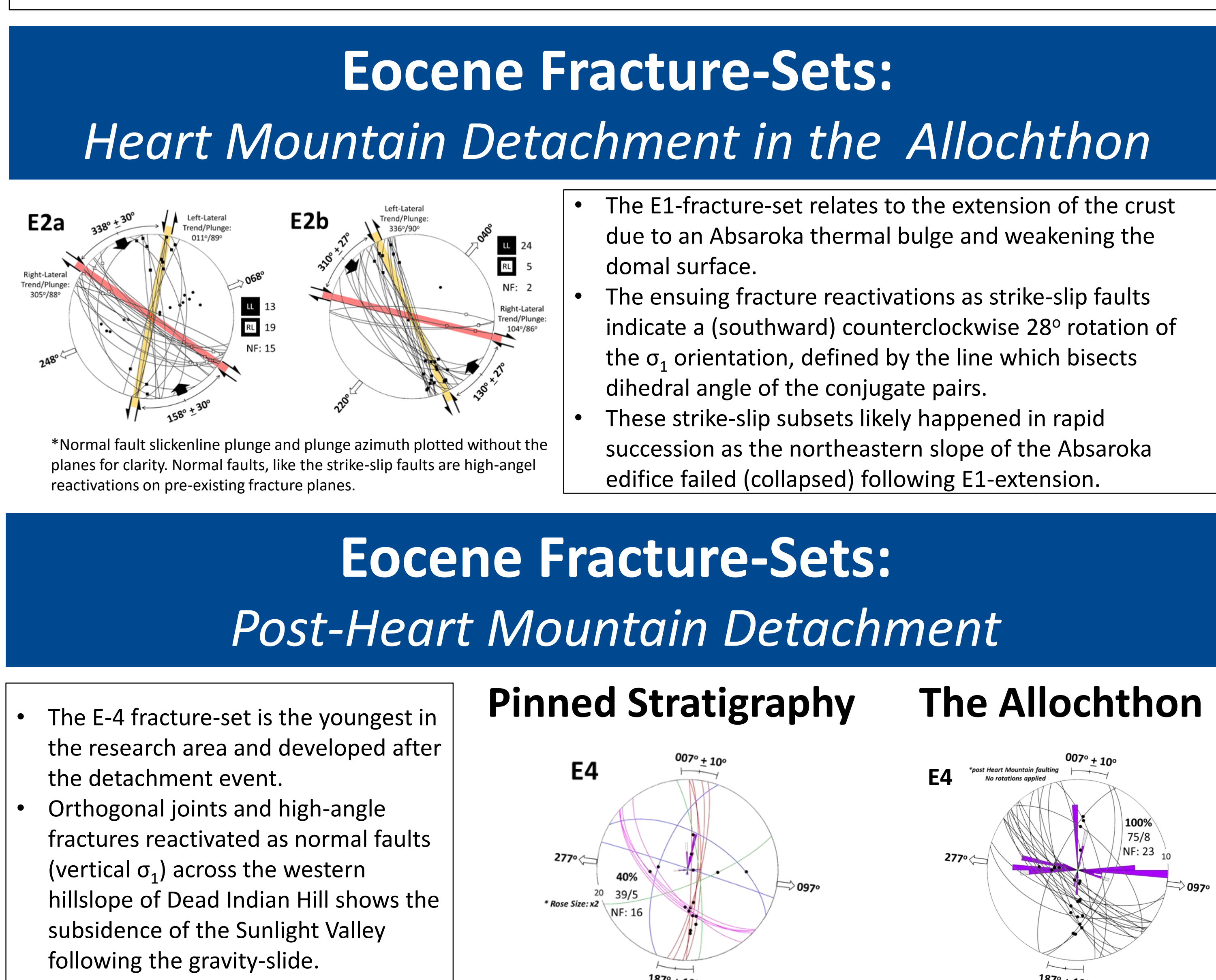

Regional Fracture-Set Continuity

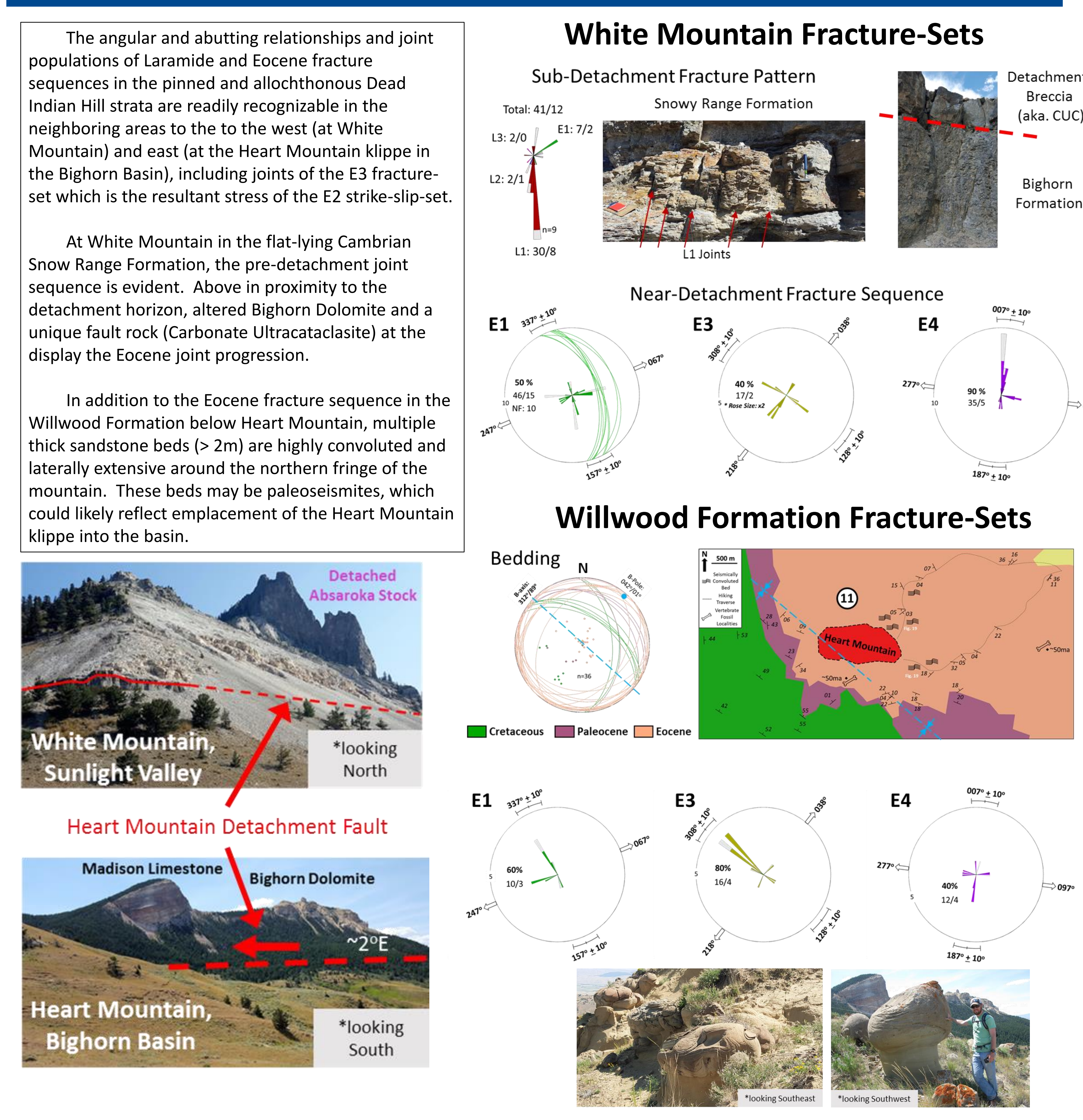

The Dead Indian Hill and the Heart Mountain Detachment Fracture Sequence
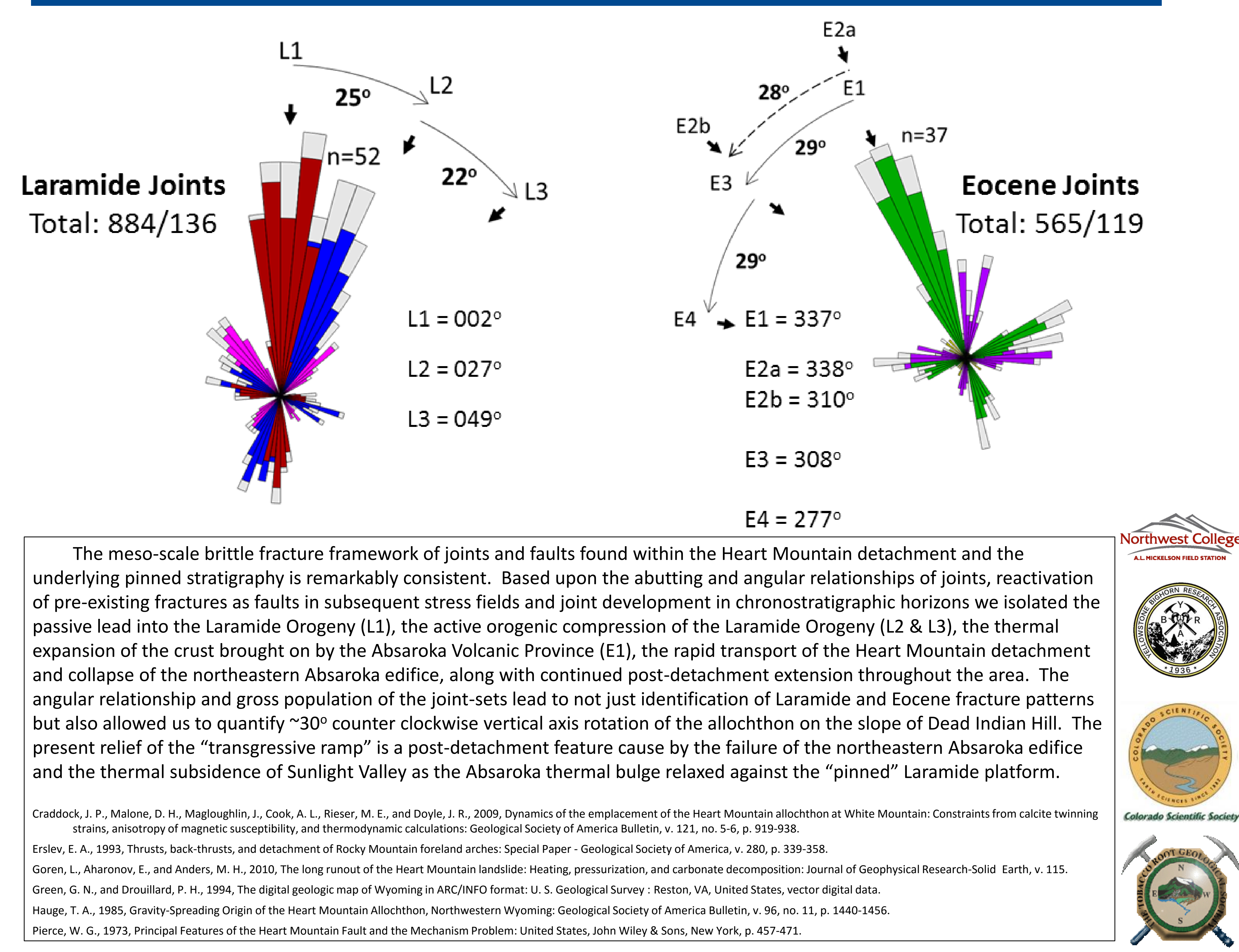

U THE UNIVESSTY OF
MEMPHIS 